Abstract AB1470HPR - Table 1. Percentage of patients who responded "strongly agree" or "agree" to the BMQ statements

\begin{tabular}{|c|c|c|c|}
\hline & $\begin{array}{c}\text { All } \\
(n=123)\end{array}$ & $\begin{array}{c}\text { Axial SpA } \\
(n=81)\end{array}$ & $\begin{array}{c}\text { PsA (n= } \\
42)\end{array}$ \\
\hline \multicolumn{4}{|l|}{ Necessity scale } \\
\hline My health, at present, depends on golimumab ${ }^{*}$ & $72.7 \%$ & $71.8 \%$ & $75.0 \%$ \\
\hline My life would be impossible without golimumab* & $51.5 \%$ & $49.3 \%$ & $57.1 \%$ \\
\hline \begin{tabular}{|l} 
Without golimumab ${ }^{*}$, I would be very ill \\
\end{tabular} & $63.6 \%$ & $60.6 \%$ & $71.4 \%$ \\
\hline My health, in the future, will depend on golimumab* & $42.4 \%$ & $46.5 \%$ & $32.1 \%$ \\
\hline Golimumab* protects me from becoming worse & $89.7 \%$ & $88.7 \%$ & $85.7 \%$ \\
\hline \multicolumn{4}{|l|}{ Concerns scale } \\
\hline Having to inject golimumab ${ }^{*}$ worries me & $29.3 \%$ & $29.6 \%$ & $28.6 \%$ \\
\hline I sometimes worry about the long-term effects of golimumab* & $49.5 \%$ & $49.3 \%$ & $50.0 \%$ \\
\hline Golimumab* is a mystery to me & $35.7 \%$ & $35.2 \%$ & $37.0 \%$ \\
\hline Golimumab $^{x}$ disrupts my life & $7.1 \%$ & $9.9 \%$ & $0.0 \%$ \\
\hline I sometimes worry about becoming too dependent on & $30.3 \%$ & $32.4 \%$ & $25.0 \%$ \\
\hline
\end{tabular}

All $p$-values $>0.1$. *For a better understanding, the commercial name was used in the patients' questionnaire

Conclusions: Patients with SpA currently using golimumab as second anti TNF-alpha describe strong beliefs in the necessity of golimumab and good experience and satisfaction with self-administration. The $B M Q$ also identified concerns that should be addressed in the clinic. The study is limited to the subset of patients still on golimumab at the study visit. Acknowledgements: Funded by Merck Sharp and Dohme, Spain Disclosure of Interest: None declared DOI: 10.1136/annrheumdis-2018-eular.2683

\section{AB1471-HPR INVESTIGATION OF THE EFFECT OF MANUAL THERAPY AND CERVICAL STABILISATION EXERCISES ON DISABILITY, KINESIOPHOBIA, DEPRESSION AND ANXIETY IN CHRONIC NECK PAIN PATIENTS: A PILOT STUDY}

\section{Y Ozel Aslıyuce, D. Onan, O. Ulger. Health of Sciences, Ankara, Turkey}

Background: Neck pain is a common pain after low back pain and becomes chronic in most of the individuals $(43 \%)$. Due to the severe pain experienced in chronic neck pain (CNP) individuals, the level of disability, depression and anxiety increases and kinesophobia develops. Cervical stabilisation exercises in individuals with CNP are one of the most effective treatment methods applied recently and the main purpose is to provide training of deep cervical muscles. Manual therapy approaches such as suboccipital release and post-isometric relaxation techniques provide relaxation of the fascia and superficial muscles. These techniques are rarely applied compared to cervical stabilisation exercises and the number of studies done in the literature is very limited. The effects of these three approaches in the treatment of pain severity, disability, kinesophobia, depression and anxiety are not known in the patients with CNP.

Objectives: The aim of this study is to investigate the effect of physiotherapy program consisting of suboccipital relaxation technique, post-isometric relaxation technique and cervical stabilisation exercises on pain severity, disability, kinesophobia, depression and anxiety in individuals with CNP.

Methods: Ten patients who have CNP aged 18-65 years (mean age $37.11 \pm 4.26$ ) were included in this study. Pain intensity at rest, activity and night with visual analogue scale (VAS), levels depression with Beck Depression Scale (BDS), anxiety with Beck Anxiety Scale (BAS), kinesiophobia with Tampa Kinesiophobia Scale (TKS) and disability with Neck Disability Index (NDI) were assessed. All participants in the study were included in a 10-session physiotherapy program that included suboccipital relaxation, post-isometric relaxation to the upper part of the trapezius muscle, and cervical stabilisation exercises.

Results: It was found that pain intensity at rest, activity and night were significantly decreased after treatment $(p=0.008)$. Disability $(p=0.008)$ and kinesophobia $(p=0.01)$ level were also significantly dropted. Depression $(p=0.015)$ and anxiety levels $(p=0.024)$ were statistically significantly improved after treatment.

Conclusions: As a result of our study, pain, depression and anxiety levels decreased, kinesophobia and disability were improved after physiotherapy applied to individuals with CNP. The suboccipital relaxation and postisometric relaxation techniques applied before cervical stabilisation exercises increased the adaptation to the exercise by providing relaxation of the painful and tense region in the patients. We think that the activation of the deep cervical muscles is facilitated when the tension of the superficial muscles and the fascia are relaxed. Soft tissue loosening does not result in pain during and-exercise, which may have reduced the tendency for kinesophobia, anxiety and depression in patients.

\section{REFERENCES:}

[1] Gelecek, N. and H. Akkan, The effect of stabilization exercise training on pain and functional status in patients with cervical radiculopathy. J Back Musculoskelet Rehabil, 2017.

[2] Strunk, R.G. and M.A. Hondras, A feasibility study assessing manual therapies to different regions of the spine for patients with subacute or chronic neck pain. J Chiropr Med, 2008. 7(1): p. 1-8.

Disclosure of Interest: None declared DOI: 10.1136/annrheumdis-2018-eular.4667

\section{AB1472-HPR INFLAMMATORY OR RHEUMATOID ARTHRITIS PATIENTS' PERSPECTIVES ON THE EFFECT OF ARTHRITIS GLOVES ON THEIR HAND PAIN AND FUNCTION (A-GLOVES TRIAL): A QUALITATIVE STUDY}

Y Prior $^{1,2}$, N. Arafin ${ }^{1}$, C. Bartley ${ }^{1}$, A. Hammond ${ }^{1} .{ }^{1}$ Health Sciences, University of Salford, Salford; ${ }^{2}$ Rheumatology, MidCheshire Hospitals NHS Trust, Leighton Hospital, Crewe, UK

Background: Arthritis (compression) gloves are frequently provided to people with inflammatory (IA) or rheumatoid arthritis (RA) in the NHS, to help reduce swelling and alleviate hand pain by providing compression and improving circulation. However evidence for their effectiveness is limited. $^{1}$

Objectives: Nested within a randomised controlled trial (RCT) testing the effectiveness of intervention (compression) gloves with control gloves (fitted at least one size too big) in people with RA and IA, this qualitative study aimed to explore patients' perspectives on the effect of the arthritis gloves on their hand pain and function.

Methods: Once randomised, participants were provided joint protection and hand exercise booklets and fitted with either the intervention or the control glove(s) by a trained occupational therapist. ${ }^{2}$ Both gloves had similar thermal qualities but control gloves did not apply compression. Semistructured interviews were conducted with 10 participants, purposively selected from each group $(n=20)$ following 12 weeks of glove wear. Interviews were audio-recorded, transcribed and analysed by three researchers using thematic analysis with a critical realist perspective.

Results: Participants' perspectives on the effects of the arthritis gloves had three emergent sub-themes. These were ${ }^{1}$ Usage: both groups predominantly used the gloves for activities such as wearing them outdoors to keep hands warm, night-time wear to help with sleep, and doing light domestic activities (e.g. dusting). Gloves were not used for cooking or washing-up or for personal activities of daily living (e.g. toileting, grooming) "What didn't help as such, obviously was with washing etc. and toileting because I had to keep taking them off and putting them back on again"," Symptomatology: while some reported that gloves helped to keep their "hand pain in check" others said that gloves had no effect on their hand pain or that they'd found "it's made them worse". Participants from both groups frequently mentioned the warmth element of the gloves, as a positive attribute to help with their symptoms; ${ }^{3}$ Aesthetics: participants had opposing views on the appearance of the arthritis gloves. Some felt that the intervention gloves "look a bit ugly with the seams outside" or stated that they "would not want to wear that colour" but did not think they were obtrusive. Most noticeably, patients seemed to view the arthritis gloves as ordinary everyday gloves, rather than a medical device "if it was cold I wore them outside".

Conclusions: Trial participants reported experiencing similar effects from wearing either the intervention or control gloves, with varied perspectives on whether or not gloves affected hand pain and/or function. Overall, patients did not reflect on the compressive but rather the thermal qualities of the gloves, as warmth was the main effect perceived.

\section{REFERENCES:}

[1] Hammond, et al. Clin Rehabil 2016 30:213-24

[2] Prior, et al. Rheum 2017(Supp1)

Acknowledgements: This project was funded by the NIHR Research for Patient Benefit Programme (PB-PG-0214-33010). The views expressed are those of the author(s) and not necessarily those of the NHS, the NIHR or the Department of Health.

Disclosure of Interest: None declared

DOI: 10.1136/annrheumdis-2018-eular.5980 